\title{
YERALTI SUYU ARAMALARINDA JEOFİİK ÖZDİRENÇ UYGULAMALARI
}

\author{
Kenan GELIŞLI', Ali Erden BABACAN
}

Karadeniz Teknik Üniversitesi, Mühendislik Fakültesi, Jeofizik Mühendisliği Bölümü, Trabzon, Türkiye

\begin{tabular}{ll}
\hline Anahtar Kelimeler & Öz \\
\hline Yeraltı Suyu, & Yeraltındaki kayaçların gözeneklerinde, çatlaklarında veya boşluklarında biriken \\
Jeofizik, & yeraltı suları yüksek kalitede ve önemli miktarlarda olabilmektedir. Birçok ülkede, \\
Elektrik Özdirenç & yeraltı suları temel içme suyu olarak, tarımsal sulamada ve endüstride \\
Tomografi. & kullanılmaktadır. Yeraltı suyu kaynaklarının haritalanması ve tatlı, tuzlu ve kirli sulu \\
& alanları belirlenmesi için jeofiziğin kullanımı, jeofizik cihazların gelişimi ve \\
& yazılımların iyileştirilmesine paralel olarak son yıllarda büyük ölçüde artmıştır. Bu \\
& çalışmada, yeraltı sularının araştırılması ve yeraltı suyu kirliliğinin belirlenmesi \\
& çalışmaları için jeofiziğin kullanımıyla ilgili genel bilgiler verilmektedir. Yeraltı suyu \\
& araştırmalarında en fazla bilgi sağlayan dolayısıyla en çok kullanılan yöntem \\
& elektrik özdirenç yöntemidir. Çalışmada bu yöntem ve yeraltı suyu aramalarında \\
& kullanımı açılanmaktadır. Ayrıca, iki farklı sahada özdirenç yöntemi ile yeraltı suyu \\
& araması ve tuzlu su girişim bölgesinin belirlenmesi ile alakalı uygulamalar \\
& sunulmaktadır. Elektrik özdirenç yöntemi ile gerçekleştirilen uygulamalar ile yeraltı \\
& suyu taşıyan tabakanın varlığı ve tuzlu su girişim alanı belirlenmiştir.
\end{tabular}

\section{GEOPHYSICAL RESISTIVITY APPLICATONS IN GROUNDWATER EXPLORATION}

\begin{tabular}{l}
\hline Keywords \\
\hline Groundwater, \\
Geophysics, \\
Electrical \\
Resistivity Tomography.
\end{tabular}

Alıntı / Cite Gelișli, K., Babacan, A.E., (2021). Yeraltı Suyu Aramalarında Jeofizik Özdirenç Uygulamaları, Mühendislik Bilimleri ve Tasarım Dergisi, 9(2), 535-543.

\begin{tabular}{l|l|l}
\hline Yazar Kimliği / Author ID (ORCID Number) & \multicolumn{3}{|l}{ Makale Süreci / Article Process } \\
\hline K. Gelişli, 0000-0002-9512-2611 & Başvuru Tarihi / Submission Date & 12.11 .2020 \\
A. E. Babacan, 0000-0002-8216-5225 & Revizyon Tarihi / Revision Date & 29.03 .2021 \\
& Kabul Tarihi / Accepted Date & 30.03 .2021 \\
& Yayım Tarihi / Published Date & 20.06 .2021 \\
\hline
\end{tabular}

\footnotetext{
* İlgili yazar / Corresponding author: gelisli@ktu.edu.tr, +90-462-377-2716
} 


\section{Giriş (Introduction)}

Dünya üzerindeki sular, okyanuslar, yeraltı suyu, göller ve akarsularda sıvı ve donmuş şekilde bulunan sulardan oluşmaktadır. Bu suların \%97,5'i tuzlu su, \%2,5 ise ise tatlı sudur. Bu tatl suyun \%68,9'u Kuzey Kutbu, Antarktika ve dağ buzullarında buz ve kalıcı kar örtüsü șeklindedir. \%30,8'i taze yeraltı suyu şeklinde bulunur (Shiklomanov, 1993). Tatlı suların büyük bir kısmından buzullar ve sürekli karlar halinde bulundukları için faydalanılamaz. Yaşamın sürdürülmesini sağlayan tatlı su kaynakları, yüzey suları olup miktar olarak da oldukça azdır. Ancak, her yerde akarsu ve göl bulunamamakta, bulunsa bile kirlilikten etkilenmiş olmakta, dolayısıyla bu durumda yeraltı sularından yararlanma yoluna gidilmektedir. Bu sebeple, özellikle kurak ve yarı kurak bölgelerde, yeraltı sularının aranıp bulunması, çok eski yıllardan beri insanları ilgilendirmektedir. Yeraltı suyu araștırmaları için jeofizik uygulamalar, genellikle yüzeyin ilk birkaç yüz metrelik derinlikleri ile sınırlıdır. Bu araştırmalarda jeofizik yöntemlerden daha çok elektrik ve elektromanyetik yöntemler kullanılmaktadır. Sı ̆̆ yeraltı suyu uygulamaları arasında, akiferlerin derinlik ve kalınlıklarının haritalanması, geçirimsiz tabaka veya sınırlayıcı birimlerin haritalanması, kırıklar ve fay zonları gibi tercihli sıvı göç yollarının konumlandırılması ve tuzlu su girişimi ve yeraltı sularına kirlilik bulaşımının haritalanması yer almaktadır. Elektrik yöntemler yapısal, litolojik, hidrojeolojik ve karstik pek çok problemin çözümünde kullanılmaktadır. Çözüm bulunabilen yapısal problemler; tabaka derinlik, kalınlık ve yayılımları, gömülü vadiler, faylar yanal geçişler, taban kaya derinliği ve özellikleri sayılabilir. Litolojik problemler; tane çapı dağılımı, yanal geçişler, çatlak, kırık zonlar, hidrolojik problemler; gözenekli tabakalar, su tablası derinliği, tatlı-tuzlu su sınırı, karstik problemler ise; karstifikasyonun tabanı, karstik zonlar, yeraltı mağara ve boşluklarıdır (Raju ve Reddy, 1998; Mohamaden ve Ehab, 2017; Kasidi, 2017).

Jeofiziğin kuramsal ve pratikgeçmişi için Grant ve West (1965), Dobrin (1976), Telford vd. (1976), Parasnis (1979) ve Kearey ve Brooks (1991) kaynaklarına bakılabilir. Yeraltı suları ve yakın yüzey araştırmaları Milsom (1996) ve Reynolds (1997) tarafından ayrıntılı olarak ele alınmıştır. Rubin ve Hubbard (2005) 'de hem hidrojeolojik hem de jeofizik bakış açısı ile hidrojeofiziğin temelleri açıklanmaktadır. Vereecken vd. (2006)'da hidrolojik süreçlerin, çözünen maddeler ve kirleticilerin su akışıyla taşınmaları ile ilgili çevre sorunlarının anlaşılması için hidrojeofizik yöntem uygulamaları üzerinde bilgiler vermektedir. Konu ile alakalı en önemli yayınlardan birisi olan Groundwater Geophysics (Yeraltı Suları Jeofiziği) isimli kitapta; jeofizik yöntemler ve gözenekli ve yapısal akiferlerin haritalanması, yeraltı suyu kalitesinin belirlenmesi, hidrolik özelliklerin değerlendirilmesi ve kirlenmiş alanların haritalanması gibi hidrojeolojik uygulamalar için bu yöntemlerin kullanımı açıklanmaktadır (Kirsch, 2009). Pellerin vd. (2009) ise hidrolojik özellikleri, yapıları ve süreçleri keşfetmek ve değerlendirmek için jeofizik metodolojilerin geliştirilmesi ve uygulanması olarak ortaya çıkan hidrojeofizik alanındaki temel bilgileri içermektedir. Yakın yüzey jeofizik uygulamaları ile ilgili bazı örnek uygulamalar SEG tarafından yayınlanan Geotechnical and Environmental Geophysics (Geoteknik ve Çevre Jeofiziği) özel serisinde bulunabilir (Ward, 1990). Yeraltı suları için jeofizik çalışmaları ile ilgili önemli yayınlar arasında "Hydrogeology of Crystalline Basement Aquifers in Africa" (Wright ve Burgess, 1992) ve "Finding Groundwater: A Project Manager's Guide to Techniques and How to Use Them" (Van Dongen ve Woodhouse, 1994) de sayllabilir.

Bu çalışmada, yeraltı suyu araştırmalarında jeofizik yöntemlerin uygulamaları ile ilgili temel bilgiler yer almaktadır. Ayrıca, iki farklı sahada elektrik özdirenç yöntemi ile yapılmış yeraltı suyu arama ve su kirliliği belirleme ile ilgili arazi örnekleri sunulmuştur.

\section{Yeraltı Suları (Groundwater)}

Yeryüzüne_düşen yağışların bir kısmı yüzeyden yer içine sızarak çeşitli derinliklerde kayaların gözenek, boşluk ve çatlaklarında depolanarak yeraltı sularını oluşturmaktadır. Yeraltı suları içme, sulama ve sanayide kullanılan doğal bir su kaynağıdır. Doğada yeraltı sularını farklı depolama ve verme özelliklerine sahip jeolojik yapılar bulunmaktadır. Yeraltı suları, kum, çakıl tanelerinin arasında, kayaçların çatlaklarında ve erime boşluklarında bulunabilir. Buna göre yeraltı sularının içinde toplandığı akiferler; alüvyonel akiferler, çatlaklı kaya akiferleri ve karstik akiferler olmak üzere üç gurupta toplanır. Ülkemiz hem yeraltı suları hem de yüzey suları bakımından dünyanın şanslı ülkeleri arasında yer alsa da nüfus artışı, hızlı sanayileşme, çarpık kentleşme, iklim değişikliği ve çölleşme gibi faktörler nedeniyle su kaynaklarımızın özellikle de yüzey sularının ciddi bir tehdit altında olduğu bilinmektedir (Akın ve Akın, 2007). Ülkemizin yüzeysel ve yer altı su kaynakları birlikte düşünüldüğünde su zengini bir ülke olmadığı anlaşılmaktadır. Su zengini ülkelerde kişi başına düşen yıllık kullanılabilir su miktarı 10.000 metreküpün üstündedir. Ülkemizdeki kişi başına düșen yıllık kullanılabilir su miktarı ise 1.350 metreküp civarındadır. 2030 yılında nüfusun 100 milyona ulaşması tahminine göre, Türkiye'de kişi başına düşen su miktarının 1.000 metreküp civarında olacağı öngörülmektedir (URL 1). Ülkemizdeki yüzey sularındaki kirlenmenin artması ve yetersiz olması nedeniyle yeraltı suyu kullanımı giderek artmaktadır. 


\section{Jeofizik Uygulamalarla Yeraltı Suyu Araștırmaları (Investigation of Groundwater with Geophysical Methods)}

Birçok jeofizik teknik yeraltı suyu araștırmalarında kullanılmaktadır. Sondaj sadece bir noktada bilgi sağlamasına rağmen jeofizik uygulamalar daha geniș bir alanda bilgi sağlarlar. Jeofizik yöntemler geleneksel yöntemlere göre erişebilirlik gibi saha olumsuzluklarından daha az etkilenirler. Jeofizik yöntemler tahribatsız olup geleneksel uygulamalara göre maliyetleri daha düşüktür. Bazı jeofizik yöntemler diğerlerinden su aramalarında daha fazla bașarı göstermektedir. Jeofizik daha çok yeraltı suyu kaynaklarının haritalanması ve yeraltı suyu kalitesini belirleme için bir araç olarak kullanılmıştır (Benson vd., 1997; Godio ve Naldi, 2003). Yeraltı suyu kaynaklarının haritalanması için, suyun bulunduğu yeraltı yapısının ortaya konulması gerekir. Genellikle gravite ve manyetik yöntemler, su aramacılığında çoğunlukla bölgesel akiferleri, büyük ölçekli havza özelliklerini haritalamak ve fay zonlarını belirlemek, sismik yöntemler ise, daha çok ana kaya akiferlerindeki kırıklı kayaç sistemlerini tanımlamak için kullanılmaktadır. Elektrik ve elektromanyetik yöntemler, özellikle yeraltı suyu arama çalışmalarında kullanılmaktadır. Tabakaların gözeneklilik, geçirgenlik, kil içeriği ve su emme gibi özelliklerinin farklı oluşu farklı özdirençlere sahip olmalarına neden olur. Özellikle boșluk biçimi ve bunları dolduran suyun özellikleri (sıcaklık, tuzluluk, kirlilik vb.) kayacın özdirencinde etkili olur. Bu yüzden elektrik ve elektromanyetik yöntemler, temiz ve kirlenmiş yeraltı sularının doğrudan haritalanması ve izlenmesinde daha başarılı sonuçlar vermektedir. Elektriksel iletkenlik ya da bunun tersi özdirenç Archie'nin çalışmasıyla (1942) gözeneklilik ile iliş kilendirilmiştir. Elektriksel iletkenlik ile kil içeriği veya akışkan tipi arasında da bir ilişki vardır (Waxman ve Smits, 1968). Bir akiferin iletkenlik ve malzeme özellikleri arasındaki ilişkiler ise Mazac vd. (1985) tarafından verilmiștir.

Van Dongen ve Woodhouse (1994) tarafından yeraltı sularının araştırılmasında jeofizik teknikler için genel uygulama yöntemleri önerilmiştir. Ancak Mac Donald vd. (2001), karmaşı jeolojiye ve hidrojeolojiye sahip olan durumlar için genel yaklaşımların yeterli sonucu vermediğini ve belirli problemler için özel yöntemlerin kullanılmasının gerektirdiğini belirtmişlerdir. Elektriksel yöntemler; kayaçların elektriksel özellikleri, jeolojik formasyonlar ve sıvı içerikleri arasındaki ilişkiler nedeniyle yeraltı suyu araştırmalarında yaygın olarak kullanılmaktadır (Flathe, 1955; Zohdy, 1969; Flathe, 1970; Ogilvy, 1970; Zohdy vd., 1974; Fitterman ve Stewart, 1986; McNeill, 1990; Mohamaden vd. 2016; Nazifi vd., 2016; Kasidi, 2017; Riwayat vd., 2018; Aziman vd., 2018; Arsene vd., 2018; Adagunodo vd., 2018; Dolmaz vd., 2020). Bugün jeofizik, yeraltı suyu araștırmasında uygulanabilecek başlıca araçtır ve başarısı, elde edilen sonuçların sahanın diğer jeolojik ve hidrojeolojik verileriyle birlikte dikkatli bir şekilde yorumlanması ve bütünleştirilmesine dayanır.

Özdirenç ölçümü için genel saha uygulaması, bir elektrik akımının yere doğrudan aktarılması (doğru akım elektriksel direnç ölçümü) ve yerde oluşan tepkiyi (elektriksel potansiyel düşüşü) belirlenen bir mesafeye göre ölçmeye dayanır. Farklı malzemelerin ve içlerindeki akışkanların elektrik akımını iletme özellikleri farklıdır. Genel olarak, yüksek kil içerikli tabakalar doymuş tabakalar gibi, özellikle tuzlu akışkanların (veya bazen başka kirlenme) mevcut olduğu tabakalar daha yüksek iletkenlik gösterir. Elektriksel yöntemler, elektrik akımını yere vermek için kullanılan elektrotların dizilimine ve kullanılan elektrik akımının türüne dayanan birtakım tiplere ayrılır. Doğru akım özdirenç yönteminde ölçü alımı biçimine göre sondaj ölçüsü, profil ölçüsü ve birleşik sondaj ölçüsü olmak üzere farklı teknikler uygulanmaktadır. Ölçülen veriler sondaj eğrileri, profil eğrileri ve yapma kesitleri şeklinde sunulur. Ayrıca iki boyutlu olarak alınmış profil verileri kullanılarak görünür özdirenç kat haritaları elde edilir. Doğru akım elektrik özdirenç yöntemi düşey elektrik sondajı (DES), tekniğin basitliği ve aletlerin ucuz olması nedenleriyle yeraltı suyu çalışmaları ile en çok kullanılan teknik olmuştur (Beeson ve Jones, 1988; Hazell vd., 1988, 1992; Van Overmeeren, 1989; Carruthers ve Smith, 1992; Wurmstich ve Morgan, 1994; Yang vd., 1994). Su bulunduran tabakalar çeşitli DES eğrileri sunarlar. DES eğri karakterlerine bağlı olarak masif olan volkanikler, kireçtaşları, kırıklı, çatlaklı kayaçlar ve içinde su olan kayaçlar belirlenebilmektedir. Yeraltısuyunun içindeki mineral oranının artması özdirenci çok düşürür. Soğuk suda ve killerde özdirenç değerleri $10 \mathrm{Ohm}$-metre'lere, tuzlu suda $0.1 \mathrm{Ohm}$-metrelere kadar düşmektedir. Sıcak sularda genellikle mineral oranı yüksek olduğundan DES eğrisindeki düşme daha ani ve keskin olmaktadır. Bol kırıklı bölgelerde ise elde edilen eğrinin çukur kısmında veya yükselen kısmında çatallanmalar oluşur. Doğal olarak bu kısımlar sondaj lokasyonu olarak düşünülmelidir. Yeraltı suyu içeren farklı ortamlar için ölçülmüş DES eğrilerine ait örnek çalışmalar Kirsch, 2006'da verilmiştir.

Geleneksel DES uygulamalarının yerini, son yıllarda çok elektrodlu özdirenç sistemi ile yapılan çalışmalar almıştır. Böylece elektriksel özdirenç tomografi (EÖT) ismi ile de bilinen bu 2B'lu yaklaşım, ölçü profili boyunca ve derinlikle de değişen özdirenç dağılımını belirlemeyi mümkün kılmaktadır. Birleşik sondaj ölçümleri ile hem yatay hem de düşey yöndeki özdirenç değişimleri birlikte araştırılır. Bu teknikle sahada ölçülen verilerden elde edilen özdirençler görünürdür. Derinlikler ve özdirenci hesaplanan noktalar göreceli olduğu için görünür özdirenç kesitleri andıran kesit (pseudosection) olarak isimlendirilir. Birleşik sondaj ölçümleri için birçok dizilim kullanılmaktadır. Sahada ölçülen akım ve potansiyel verilerinden hesaplanan görünür özdirençler konturlanarak haritalar oluşturulur. Çizilen bu haritalar üzerinden nitel yorum yapılabilir. Elde edilen kesit hem yanal yönde hem 
de düşey yönde yer içinin 2 Boyutlu özdirenç yapısı hakkında bilgi vermektedir. Nicel yorum için ise, görünür özdirenç yapma kesit verilerinin 2B ters çözümünün yapılması gerekir. Elektrik özdirenç tomografisi veya elektrik özdirenç görüntüleme olarak da isimlendirilen bu teknikte, 2B bir modelin ardışık yaklaşımla (iterative inversion) teorik andıran kesiti hesaplanıp saha andıran kesitine çakışması sağlanır. Bu teknik yeraltının göreceli olarak bir fotoğrafını sunduğu için yeraltı suyu aramalarında da yaygın olarak kullanılmaktadır (Olayinka ve Barker, 1990; Dahlin ve Owen, 1998; Beeson ve Jones, 1988; Zonge vd., 1985; Bartel, 1986; Buselli vd., 1988, 1992; Hazell vd., 1988; Saksa ve Paananen, 1992; Sorensen ve Sondergaard, 1999; Van Overmeeren, 1981, 1989 ve 1998; Riwayat vd., 2018). Yeraltı suyu arama çalışmalarında ilgili formasyonlar üzerinde mümkünse mostra ölçüleri alınmalı, arazide varsa mevcut kuru veya su alınan sondaj kuyuları üzerinde bilgi amacıyla ölçüler yapılarak sahanın karakteri anlaşılmaya çalışılmalıdır. Ölçülerin değerlendirilmesiyle yeraltı düşey kesitleri hazırlanmalıdır. Alüvyoner akiferlerde alüvyon kalınlık haritaları hazırlanmalı, alüvyonun bloklu, çakıllı, kumlu killi ve siltli bölümleri ayırtlanmaya çalışılmalıdır. Çatlaklı kaya akiferlerinde kayaçların kırık-çatlak içeren bölümleri, karstik akiferlerde ise karstik erime zonları belirlenmelidir. Killi bölgelere özellikle dikkat edilmelidir. Çünkü düşük özdirenç değeri gösteren killer suyu emer, șișer, fakat kile su sondajı verilmez. Cünkü geçirgenliği çok düșük olduğu için kilden su zor alınır. Herhangi bir jeofiziksel araştırmanın bașarısının anahtarı, jeofizik verilerin hem hidrojeolojik hem de jeolojik bilgiler ile doğrulanmasıyla doğrudan ilgilidir.

\subsection{Elektrik Özdirenç Arazi Uygulama Örnekleri (Electrical Resistivity Field Application Examples)}

Bu çalışmada örnek olarak iki farklı sahada (Araklı ve Değirmendere, Trabzon) sulama amacıyla yapılan yeraltı suyu araştırmalarında alınan ölçümlerden dört profile ait EÖT veri sonuçları sunulmuştur. Çalışma alanları Doğu Karadeniz bölgesinde Trabzon il sınırları içerisinde yer almaktadır (Şekil 1a, b). Çalışma alanlarının jeolojisine yönelik ayrıntılı bilgiler Güven, 1993 ve Güven vd., 1993 tarafından verilmiştir. Her iki sahada da Eosen yaşlı bazalt ve andezitlerden oluşan Kabaköy formasyonu geçirimsiz kaya özelliğindendir (Şekil 1a, b). Ölçü alınan sahaların hidrojeolosine yönelik ayrıntılı bilgiler Dilek, 1979 ve Aydoğan, 1987' de verilmiştir. Her iki sahada yer alan kalınlığı 25-40 metre arasında değișen alüvyonlar serbest akifer niteliğindedir (Gültekin vd., 2005). Büyük oranda çakıl, az kum ve çok az siltten oluşan akiferler yüksek porozite ve permabiliteye sahiptir. Araklı ilçesindeki ölçümler sahil kesiminde denize oldukça yakın bir bölgede alınmıștır. Bu alan genel olarak Karadere ve Küçükdere nehirlerinin getirdiği Kuvarterner yaşlı alüvyonlardan oluşmakta olup, su içeren zonlar bu birim içerisinde kalmaktadır (Şekil 1b). Diğer uygulama örneğimiz Trabzon ilinin doğusunda yer alan Değirmendere nehrinin denize döküldüğ̈ kısma yakın bir alana aittir. Bu alanda da benzer olarak akifer tabakası Değirmendere'nin getirdiği Kuvarterner yaşlı alüvyonlarda yer almaktadır (Şekil1a). 


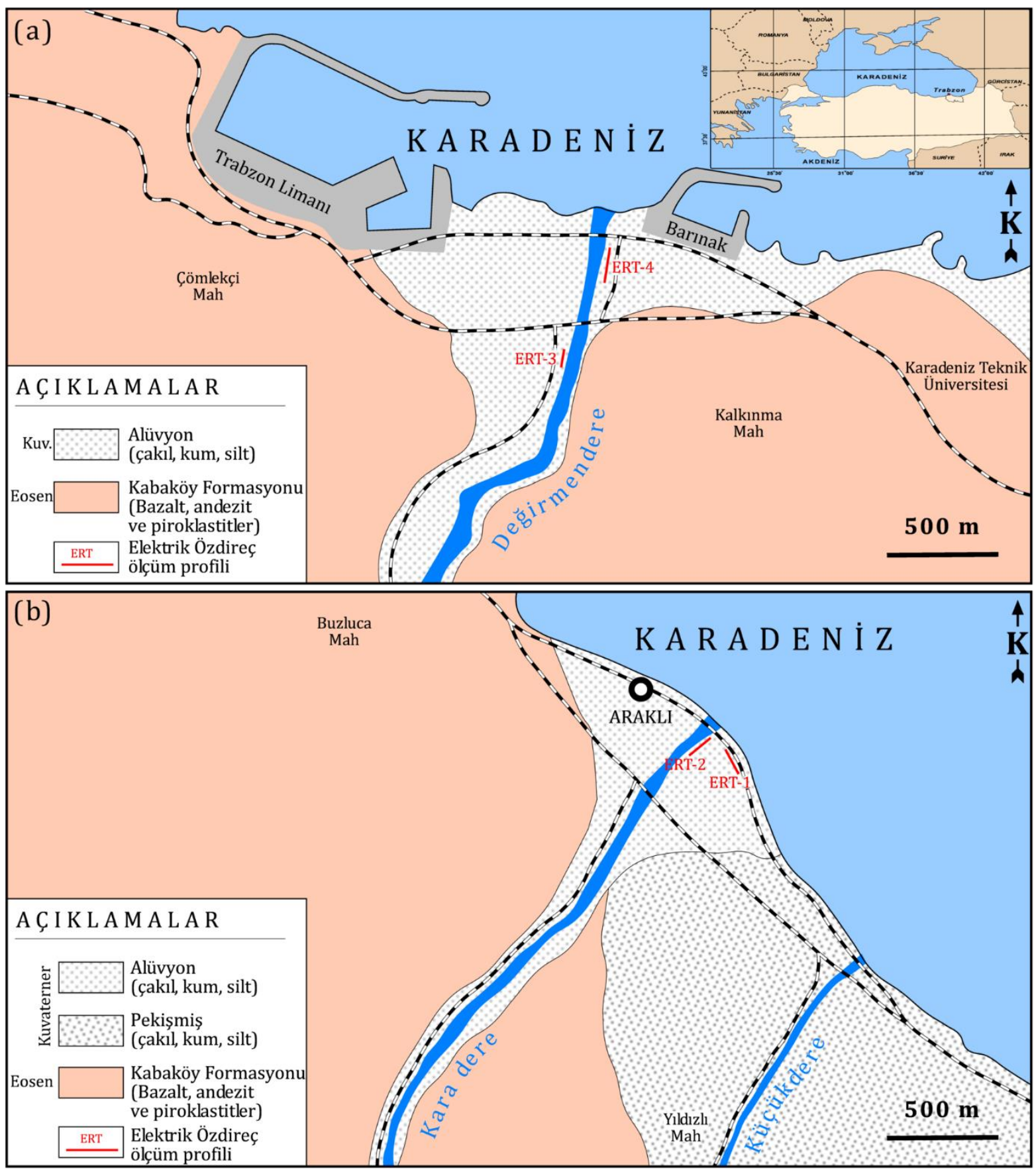

Şekil 1. Çalışma alanlarının jeoloji haritaları (a) Değirmendere, (b) Araklı (Güven, 1993’ten değiştirilerek) (Geological maps of studied areas (a) Değirmendere, (b) Araklı)

2B EÖT ölçümlerinde, çok kablolu bir sisteme bağlı birçok potansiyel ve akım elektrotunun bir kombinasyonunu kullanır. Bu sistem, bir etüt hattı boyunca belirli aralıklarla yere yerleştirilir ve ölçümler otomatik olarak yapılmaktadır. Ölçümler 41 elektrot kullanılarak ABEM Terrameter LS cihazı ile alınmış ve dizilim olarak WennerSchlumberger dizilimi seçilmiştir. Bu dizilim türü hem yanal hem düşey yöndeki yapıların özdirenç değişimine karşı daha hassastır. Aynı zamanda karmaşık jeolojik koşullarda Wenner ve Dipol-Dipol dizilimlerinden daha fazla umut vericidir (Loke, 2000). Araklı sahasında elektrot aralıkları $2.5 \mathrm{~m}$ iken, Değirmendere'de birinci profilde 1.8 m ikinci profilde ise $4 \mathrm{~m}$ olarak belirlenmiştir. Elde edilen görünür özdirenç kesitleri Res2Dinv ters çözüm programı kullanılarak değerlendirilmiştir (Şekil 2, 3). İterasyon sayıları ve RMS hata oranları șekiller üzerinde verilmiştir. Res2Dinv programı, kullanıcı tarafından tanımlanan çok az giriş parametresiyle, olabildiğince otomatik ve doğru sonuçlar verecek şekilde tasarlanmış 2B bir ters çözüm programıdır (Loke, 2000). Program, temel olarak en küçük kareler yöntemini ters çözüm tekniği olarak kullanır (DeGroot-Hedlin ve Constable, 1990). 


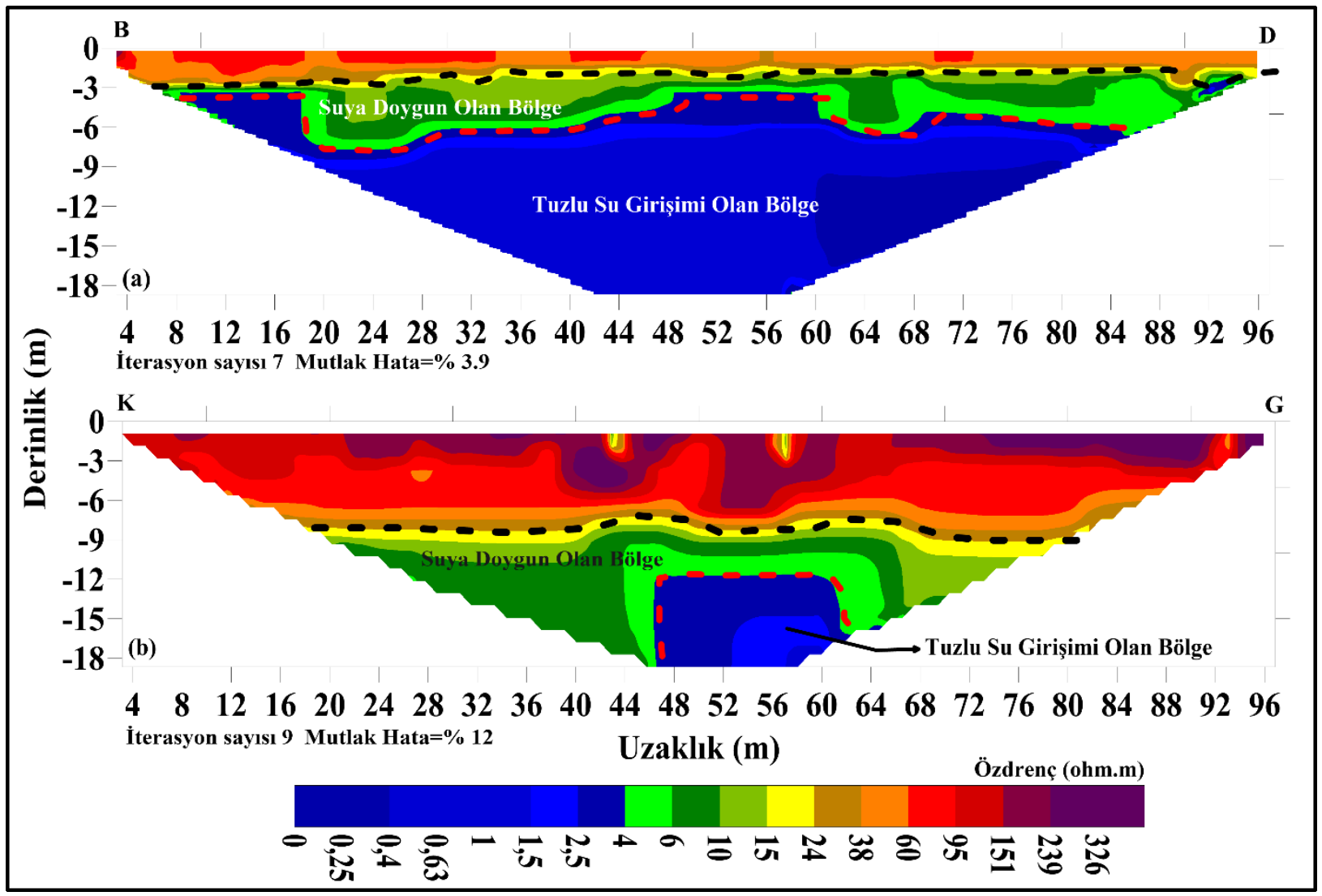

Şekil 2. Araklı ilçesi sahil kenarında iki kısımda alınan 2B EÖT kesitleri (a) sahile paralel alınan özdirenç kesiti (EÖT 1), (b) sahile dik dere yatağının hemen yanında alınan özdirenç kesiti (EÖT-2) (2D ERT sections taken in two parts of the coast of Araklı district (a) resistivity section taken parallel to the coast (ERT-1), (b) resistivity section taken right next to the stream bed perpendicular to the coast (ERT-2))

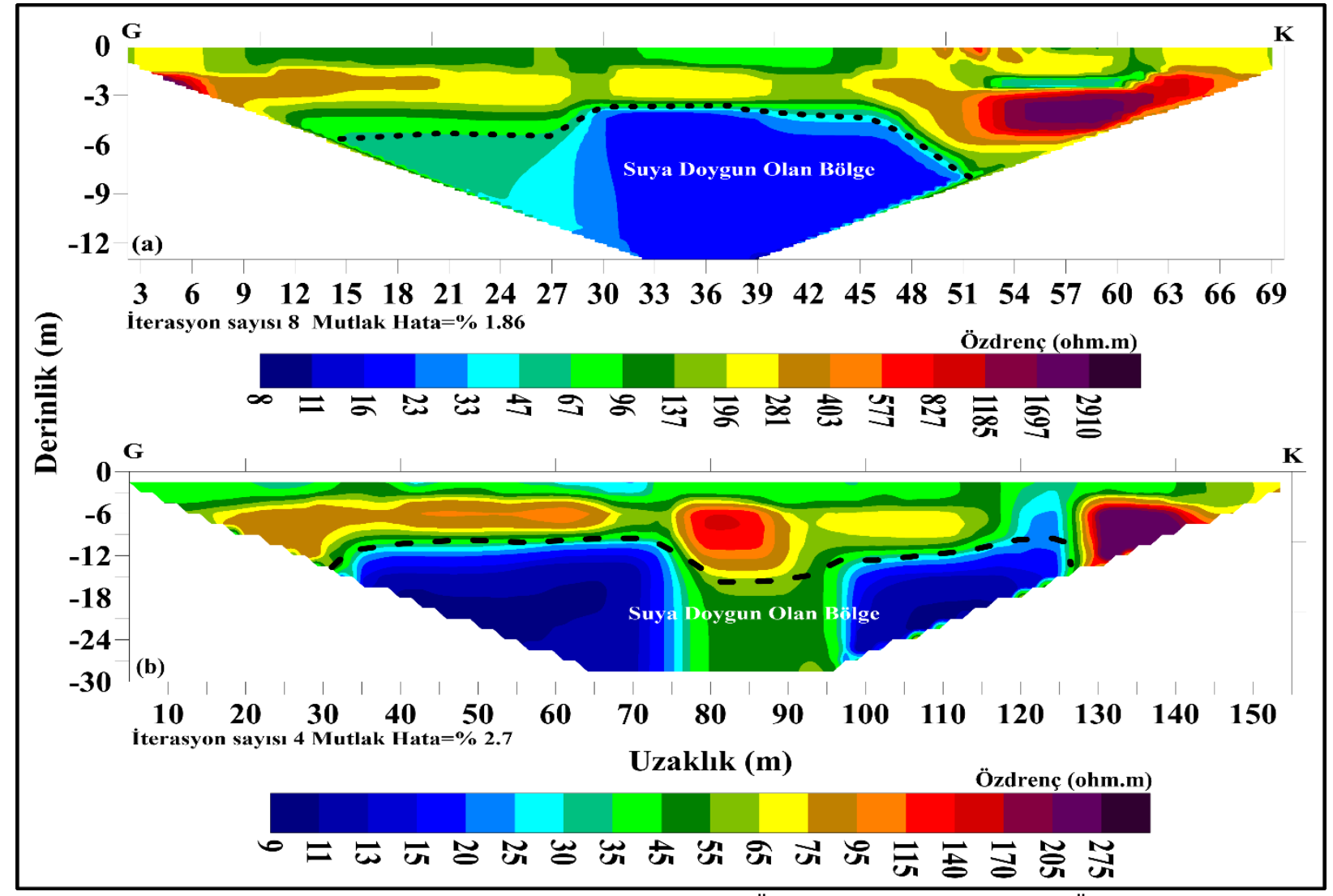

Şekil 3. Trabzon Değirmendere mevkiinde iki kısımda alınan 2B EÖT kesitleri (a) 3. profile ait EÖT kesiti, (b) 4. profili ait EÖT kesiti (2D ERT sections taken in two parts at Trabzon Değirmendere location, (a) ERT section of profile 3, (b) ERT section of profile 4 ) 


\section{Sonuç ve Tartışma (Result and Discussion)}

Bu çalışmada jeofizik yöntemler ile su aramaları konusunda temel bilgilerle birlikte bu uygulamalarda dikkat edilecek hususlarla ilgili olarak bazı bilgiler verilmiș ve elektrik özdirenç yöntemiyle yeraltı suyu araması ve tuzlu su girişiminin varlı̆̆ının araștırılması ile alakalı uygulamalar sunulmuștur. Çalışmada, örnek olarak Trabzon ili Araklı ilçesinin sahil kesiminde ve Trabzon merkez Değirmendere mevkiinde olmak üzere iki farklı alanda, alüvyon kalınlığı, yeraltı su seviyesinin derinliği ve tuzlu su girişiminin belirlenmesi amacıyla alınan ölçülerden dört profile ait 2B EÖT ölçülerinin sonuçları sunulmuştur. İnceleme alanlarının jeolojik ve hidrojeoljik özellikleri göz önünde bulundurularak elde edilen tomografi kesitleri yorumlanmıştır.

Araklı sahasındaki Jeoelektrik verilerin yorumlanması sonucuna göre, her iki profilde yaklaşı $19 \mathrm{~m}$ derinlikten bilgi alınabilmesine rağmen ana kaya derinliği belirlenememiştir. EÖT kesitleri çalışma alanın oldukça kalın bir dolgu malzemesi olduğunu göstermektedir. Çevrede yapılan gözlemler ve daha önceden yapılmış sondajlar ile de bu bilgi teyit edilmiştir. Kuru birimin kalınlığı yaklaşık $3 \mathrm{~m}$ civarında ve özdirenç değerleri $40 \mathrm{Ohm} . \mathrm{m}$ nin üzerindedir. Bu birimin altında ise kalınlığı 3 ila yaklaşık 7.5 m arasında, özdirenç değerleri ise 5-40 Ohm.m arasında değișen tatlı suya doygun birim yer almaktadır. En altta ise derinliği 19 metrelere kadar inen, özdi renci 4 Ohm.m den daha düşük ve alanın büyük bir kısmına yayılmıș tuzlu su girişimi olan bölgenin varlığı gözlenmiştir. Özellikle denize yakın alanlarda yapılan EÖT ölçümlerinde özdirenç değerlerinin 1 Ohm.m lerin altına düşmesi, sahanın jeolojik ve hidrojeolojik özellikleri de dikkate alındığında tuzlu su girişimin olduğunun göstergesidir. İkinci profilde derinliği yüzeyden 9 metrelere kadar inen, özdirenci 40 Ohm.m'nin üstünde olan kuru bir birim, onun altında ise derinliği 19 metrelere kadar inen, özdirenci 5-40 Ohm.m arasında değișen tatlı suya doygun birimin varlığı görülmektedir. Ayrıca bu kesitte yüzeyde, profil başlangıcından 47-62 metreler arasında, derinliği 12 ile 19 metreler arasında değișen tuzlu su girişimin varlığı gözlenmektedir. 2 boyutlu EÖT kesitlerinden, birinci profil alanında tuzlu su girișiminin profil boyunca varlığı gözlenirken, diğer profilde kısmen denize daha uzak olması ve nehre daha yakın olması nedenleri ile tuzlu su girişiminin daha dar bir alanda varlığı gözlenmiştir. Elde edilen sonuçlar bu alanda açılacak kuyulardan elde edilen yeraltı suyunun tuzluluk nedeniyle sulamada kullanımının mümkün olmayacağını göstermektedir.

Değirmendere mevkiinden elde edilen verilerin değerlendirilmesi sonucu, birinci profilde yaklaşık $13 \mathrm{~m}$, ikinci profilde ise yaklaşık $30 \mathrm{~m}$ derinliklerinden bilgi alınabilmiştir. Her iki kesitte de ana kaya varlığı gözükmemekle beraber özellikle ikinci profilden elde edilen EÖT kesitine göre çalışılan sahada alüvyon kalınlığının oldukça fazla olduğu anlaşılmaktadır. Her iki kesitte de yer yer görülen oldukça yüksek özdirenç değerleri yüzeyde nispeten kuru birimlerin varlığına işaret etmektedir. Birinci kesitte alüvyonun tatlı suya doygun kesimi 5-6 m derinliklerden başlayıp 13 metrelere kadar devam etmektedir. Bu birimin özdirenci 8-50 Ohm.m ler arasında değişmektedir. İkinci profilde ise tatlı suya doygun bölge 9-10 metre derinliklerinden başlayıp $30 \mathrm{~m}$ derinliğine kadar inmektedir. Bu birimin özdirençleri ise 9-55 Ohm.m ler arasındadır. Bu alandaki sonuçlara göre açlacak kuyulardan elde edilecek olan yeraltı suyunu sulama amaçlı kullanmak mümkündür. Bu bölgede önceleri var olan belediyeye ait yüksek debili içme suyu kuyuları, kuyuların uzun süre kullanımından kaynaklanan bozulmalar nedeniyle daha sonraları kapatılmıştır.

Sonuç olarak, elektrik özdirenç çalışması ile yapılan yeraltı suyu araștırması, yeraltı suyunu taşıyan akiferin yeri ve kalınlığı, tatlı su-tuzlu su girişim alanı başarıyla tespit edilmiştir. Bu uygulama kısa zamanda, düşük bir maliyetle oldukça kapsamlı veri sağlamaktadır. Ancak uygulamanın başarısı, veri toplama, işleme ve yorumlamada birçok değişkene bağlı olduğu için, bu konuda bilgili ve deneyimli kişiler tarafından gerçekleştirilmesine bağlıdır.

\section{Teşekkür (Acknowledgement)}

Yazarlar arazi verilerinin toplanmasında yardımcı olan KTÜ Jeofizik mühendisliği bölümü öğrencilerine teșekkür ederler. Yazarlar ayrıca makaleyi geliştirmedeki yararlı ve yapıcı yorumları için Editöre ve hakemlere de teşekkür ederler.

\section{Çıkar Çatıșması (Conflict of Interest)}

Yazarlar tarafından herhangi bir çıar çatışması beyan edilmemiştir. No conflict of interest was declared by the authors.

\section{Kaynaklar (References)}

Adagunodo, T. A., Akinloye, M. K., Sunmonu, L. A., Aizebeokhai, A. P., Oyeyemi, K. D., Abodunrin, F. O. 2018. Groundwater Exploration in Aaba Residential Area of Akure, Nigeria, Front. Earth Sci., 06 https://doi.org/10.3389/feart.00066. 
Akın, M., Akın, G. 2007. Suyun önemi, Türkiye'de su potansiyelii su havzaları ve su kirliliği, Ankara Üniversitesi Dil ve TarihCoğrafya Fakültesi Dergisi, 47, 105-118.

Archie, G. E. 1942. The Electrical Resistivity Log as an Aid in Determining Some Reservoir Characteristics, Transactions of the AIME, 146, 54-62.

Arsene, M., Elvis, B. W. W., Daniel, G., Théophile, N-M., Kelian, K., Daniel, N.J. 2018. Hydrogeophysical Investigation for Groundwater Resources from Electrical Resistivity Tomography and Self-Potential Data in the Méiganga Area, Adamawa, Cameroon, International Journal of Geophysics, Hindawi, Article ID 2697585, 14 pages https://doi.org/10.1155/2018/2697585.

Aydoğan, B. 1987. Değirmendere (Hacımehmet-Çağlayan) Vadisi hidrojeolojik incelemesi, KTÜ, Jeoloji Müh. Böl. Bitirme Calıșması (yayınlanmamıș).

Aziman, M., Hazreek, Z. A. M., Azhar, A. T. S., Fahmy, K. A., Faizal, T. B. M., Sabariah, M., Ambak, K., Ismail, M .A. M. 2018. Electrical Resistivity Technique for Groundwater Exploration in Quaternary Deposit, IOP Conf. Series: Journal of Physics: Conf. Series, 995, 012110

Bartel, L. C. 1986. Electrical and electromagnetic model studies as applied to groundwater problems, Annual Meeting Abstracts, Society of Exploration Geophysicists, Session: ENG2.3.

Beeson, S., Jones, C. R. C. 1988. The Combined EMT/VES Geophysical Method for Sitting Boreholes, Ground Water, 26 (1), $54-$ 63.

Benson, A.K., Payne, K.L., Stubben, M.A. 1997. Mapping groundwater contamination using DC resistivity and VLF geophysical methods-a case study, Geophysics, 62, 80-86.

Buselli, G., Barber, C. and Zerilli, A. 1988. "The mapping of groundwater contamination with TEM and DC methods", ASEG 13th Geophysical Conference, Australian Society of Exploration Geophysicists, 19, 240-243.

Buselli, G., Davis, G. B., Barber, C., Height, M. I., Howard, S. H. D. 1992. The application of electromagnetic and electrical methods to groundwater problems in urban environments, Exploration Geophysics, 23 (4), 543-555.

Carruthers, R. M., Smith, I. F. 1992. The Use of Ground Electrical Methods for Siting Water Supply Boreholes in Shallow Crystalline Basement Terrains. In: E. P. Wight and W. G. Burgess, (eds), The Hydrogeology of Crystalline Basement Aquifers in Africa, Geological Society Special Publication, 66, 203-220.

Dahlin, T., Owen, R. 1998. Geophysical investigations of alluvial aquifers in Zimbabwe. Proceedings of the 4th EEGS Meeting, Barcelona, 151-154.

DeGroot-Hedlin, C., Constable, S. 1990. Occam's inversion to generate smooth, two-dimensional models from magnetotelluric data, Geophysics, 55, 1613-1624.

Dilek, R. 1979. Trabzon- Hopa kıyı șeridinin yeraltı suyu olanaklanakları, KTÜ Yayın No: 99, Trabzon

Dobrin, M. B. 1976. Introduction to Geophysical Prospecting, New York, McGraw-Hill, p. 630.

Dolmaz, M.N., Şahin, B., Tütünsatar, H.E., Balkaya, C.. 2020. Afyon-Sandıklı Jeotermal Alanında Düșey Elektrik SOndaj (DES) Araştırması ve Kuyuların Fiziksel Özellikleri, Mühendislik Bilimleri ve Tasarım Dergisi, 8(2), 439-450.

Fitterman, D. V., Stewart, M. T. 1986. Transient Electromagnetic Sounding for Groundwater, Geophysics, 51 (4), $995-1005$.

Flathe, H. 1955. Possibilities and Limitations in Applying Geoelectrical Methods to Hydrogeological Problems in the Coastal Areas of North west Germany, Geophysical Prospecting, 3, 95-110.

Flathe, H. 1970. Interpretation of Geoelectrical Resistivity Measurements for Solving Hydrogeological Problems. In Morely, E. W. (ed.), Mining and Groundwater Geophysics, Geological Survey of Canada Economic Geological Report, 26, 580-597.

Godio, A., Naldi, M. 2003. Two dimensional electrical imaging for dedection of hydrocabon contaminats, Near Surface Geophysics, 1,131-137.

Grant, F.S., West, G.F. 1965. Interpretation Theory in Applied Geophysics, McGraw-Hill, New York.

Gültekin, F., Dilek, R., Ersoy, A.F., Ersoy, H. 2005. Așağı Değirmendere (Trabzon) Havzasındaki Suların Kalitesi, Jeoloji Mühendisliği Dergisi, 29(1).

Güven, İ.H. 1993. Doğu Pontidlerin Jeolojisi ve 1/250.000 ölçekli kompilasyonu. MTA Yayınları, Ankara, Türkiye.

Güven, İ.H., Nalbantoğlu, A.K., Takaoğlu, S. 1993. MTA Genel Müdürlüğü, 1/100.000 ölçekli açınsama nitelikli Türkiye jeolojisi haritaları serisi, Trabzon F43 ve G43 paftaları, Ankara, (Yayınlanmamış).

Hazell, J. R. T., Cratchley, C. R., Jones, C. R. C. 1992. The hydrogeology of Crystalline Aquifers in Northern Nigeria and Geophysical Techniques used in their Exploration. In: E. P. Wight and W. G. Burgess, (eds), The Hydrogeology of Crystalline Basement Aquifers in Africa, Geological Society Special Publication, 66, 155-182.

Hazell, J. R. T., Cratchley, C. R., Preston, A. M. 1988. The Location of Aquifers in Crystalline Rocks and Alluvium in Northern Nigeria using Combined Electromagnetic and Resistivity Techniques, Quarterly Journal of Engineering Geology, 21, 159175.

Kasidi, S. 2017. Groundwater Exploration Using Electrical Resistivity Method A Case Study In Federal Capital Territory (FCT) Abuja. Nigeria, International Journal of Engineering and Applied Sciences (IJEAS), 4 (10), 1-8.

Kearey, P., Brooks, M. 1991. An Introduction to Geophysical Exploration, 2nd Editions, Blackwell Scientific Publications, Oxford, 254

Kirsch, R. 2009. Groundwater Geophysics, A Tool for Hydrogeology, Springer.

Loke, M. H. 2000. Electrical imaging surveys for environmental and engineering studies, a practical guide to 2-D and 3-D surveys. geoelectrical.com.

Mac Donald, A. M., Calow, R. C., Nicol, A., Hope, B., Robins, N. S. 2001. Ethiopia: water security and drought, British Geological Survey, Technical Report WC/01/02.

Mazac, O., Kelly, W. E., Landa, I. 1985. A hydrogeophysical model for relations between electrical and hydraulic properties of aquifers, J Hydrol., 79, 1-19.

McNeill, J. D. 1990. Use of Electromagnetic Methods for Groundwater Studies. In: Ward, S. H. (Ed.). Geotechnical and Environmental Geophysics, vol 1: Review and Tutorial, Society of Exploration Geophysicists Investigations, 5, 107-112.

Milsom, J. 1996. Field Geophysics, Geological Society of London handbook. Open University Press and Halsted Press. Wiley and Sons, Chichester. 
Mohamaden, M. I. I., Ehab, D. 2017. Application of electrical resistivity for groundwater exploration in Wadi Rahaba, Shalateen, Egypt, NRIAG Journal of Astronomy and Geophysics Volume 6 (1), 201-209.

Mohamaden, M. I. I., Hamouda, A. Z., Mansour, S. 2016. Application of electrical resistivity method for groundwater exploration at the Moghra area,Western Desert, Egypt, The Egyptian Journal of Aquatic Research, m42 (3), 261-268.

Nazifi, H. M., Gülen, L., Karavul, C. 2016. Groundwater investigations in Ghana using electromagnetic and electrical resistivity methods, SAÜ Fen Bil Der., 20( 2), 133-139.

Ogilvy, A. A. 1970. Geophysical Prospecting for Groundwater in the Soviet Union, in Morely E. W. (ed.), Mining and Groundwater Geophysics, Geological Survey of Canada Economic Geological Report, no. 26, 536-543.

Olayinka, A., Barker, R. 1990. Borehole Siting in Crystalline Basement Areas of Nigeria with a Microprocessor Controlled Resistivity Traversing System, Groundwater, 28, 178-183.

Parasnis, D.S. 1979. Principles of Applied Geophysics, Chapman and Hall. 275.

Pellerin, L., Holliger, K., Slater, L., Yaramancı, U. 2009. Hydrogeophysics-Methods and Processes, EAGE.

Raju, N., Reddy, T.V.K. 1998. Fracture pattern and electrical resistivity studies for groundwater exploration, Environmental Geology 34, 175-182.

Reynolds, J. 1997. Introduction to Applied and Environmental Geophysics, John Wiley and Sons.

Riwayat, A. I., Nazri, M. A. A., Abidin, M. H. Z. 2018. Application of Electrical Resistivity Method (ERM) in Groundwater Exploration, IOP Conf. Series: Journal of Physics: Conf. Series, 995012094.

Rubin, Y., Hubbard, S.S. (eds). (2005). "Hydrogeophysics", Springer, The Netherlands.

Saksa, P., Paananen, M. 1992. Case study: Mapping of groundwater conditions at Olkiluoto site with electrical and electromagnetic soundings, 61st Mtg. Eur. Assoc. Expl Geophys., Extended Abstracts, European Association of Geophysical Exploration, 694-695.

Shiklomanov, L.A. 1993. World Freshwater Resources. In: Gleick, P.H. (Ed), Water in Crisis: A Guide to World's Freshwater Resources, Oxford University Press, New York, 13-24.

Sorensen, K. I., Sondergaard, V. H. 1999. Large-Scale Geophysical Mapping and Its Application for Ground Water Protection in Urban Areas, In: Proceedings for SAGEEP, Oakland, CA, 481-486.

Telford, W. M., Geldart, L .P., Sheriff, R. E., Keys, D. A. 1976. Applied Geophysics, Cambridge University Press.

URL-1, https://www.mfa.gov.tr/turkiye_nin-su-politikasi.tr.mfa (Erişim Tarihi:30.10.2020).

Van Dongen, P., Woodhouse, M. 1994. Finding Groundwater: A Project Manager's Guide to Techniques and How to Use Them,

World Bank Water and Sanitation Program.

Van Overmeeren, R. A. 1981. A combination of electrical resistivity, seismic refraction, and gravity measurements for groundwater exploration in Sudan, Geophysics, 46 (9), 1304-1313.

Van Overmeeren, R. A. 1989. Aquifer boundaries explored by geoelectrical measurements in the coastal plain of Yemen: A case of equivalence, Geophysics, 54 (01), 38-48.

Van Overmeeren, R. A. 1998. Radar facies of unconsolidated sediments in The Netherlands: A radar stratigraphy interpretation method for hydrogeology, Journal of Applied Geophysics, 40(1-3), 1-18.

Vereecken, H., Binley, A., Cassiani, G., Revil A., Titov K. 2006. Applied Hydrogeophysics. In: Vereecken H., Binley A., Cassiani G., Revil A., Titov K. (eds) Applied Hydrogeophysics, NATO Science Series, vol 71. Springer, Dordrecht. https://doi.org/10.1007/978-1-4020-4912-5_1.

Ward, S.H. (ed). 1990. Geotechnical and Environmental Geophysics: Volume I-III - SEG investigations in Geophysics, Tulsa, Okla, 1050.

Waxman, M. H., Smits, L. J. M. 1968. Electrical Conductivities in Oil-Bearing Shaly Sands, Society of Petroleum Engineers Journal, $8,107-122$.

Wright, E. P., Burgess, W. G. 1992. The Hydrogeology of Crystalline Basement Aquifers in Africa, Geological Society Special Publication, No. 66. London.

Wurmstich, B., Morgan, F. D. 1994. Similarities in modeling groundwater flow and DC resistivity, Annual Meeting Abstracts, Society of Exploration Geophysicists, 578-579.

Yang, C., Tong, L., Jeng, L. 1994. Locating groundwater at selected sites by geoelectric methods, Annual Meeting Abstracts, Society of Exploration Geophysicists, 652-654.

Zohdy, A.A. 1969. A new method for differential resistivity sounding. Geophysics, 34 (6), 924-943.

Zohdy, A.A., Eaton, C.P., Mabey, D.R. 1974. Application of Surface Geophysical to Ground Water Investigation Technology. Water Resources Investigation, Washington, U.S Geological survey.

Zonge, K. L., Figgins, S. J., Hughes, L. J. 1985, Use of electrical geophysics to detect sources of groundwater contamination. Presented at the 55th Ann. Internat. Mtg., Soc. Expl. Geophys. 147-149. 